\title{
Modelling the concentrations of $\mathrm{PM}_{10}$ at a roadside site using data from a nearby background site
}

\author{
D. Muir ${ }^{1} \&$ J. W. S. Longhurst ${ }^{2}$ \\ ${ }^{1}$ Environmental Quality Unit, Department of Environment, \\ Transport \& Leisure, Bristol City Council, UK \\ ${ }^{2}$ University of the West of England, Bristol, UK
}

\begin{abstract}
It has been demonstrated elsewhere that it is possible to identify the most probable source of $\mathrm{PM}_{10}$ during air pollution episodes by examining the relationships between the additional amounts of $\mathrm{PM}_{10}$ and other, gaseous, pollutants. The work described here develops this to model the concentrations of $\mathrm{PM}_{10}$ at the Glasgow Kerbside monitoring site using a combination of nitric oxide data from that site and data for ozone, nitrogen dioxide, sulphur dioxide and $\mathrm{PM}_{10}$ from the nearby Glasgow Centre monitoring site.

Keywords: $P M_{10}$, Air Quality management, road traffic, modelling.
\end{abstract}

\section{Introduction}

Part IV of the Environment Act, 1995, requires Local Authorities in the UK to review and assess air quality in their administrative areas at regular intervals as part of the process of Local Air Quality Management (LAQM). For this purpose objectives have been set for concentrations of seven pollutants to be achieved by a number of target dates. If this process indicates that one or more of these will not be met then the authority must declare an Air Quality Management Area (AQMA) and develop an Air Quality Action Plan (AQAP) to introduce local measures, over and above proposed national measures, to attempt to meet the objectives. The objectives are based on European Air Quality Limit Values (where formulated) supplemented by recommendations from the UK Expert Panel on Air Quality Standards (EPAQS). The pollutants are benzene, 1,3 butadiene, carbon monoxide, lead, nitrogen dioxide, particles measured as $\mathrm{PM}_{10}$ 
and sulphur dioxide. By October 2004123 AQMAs had been declared, 61 for $\mathrm{NO}_{2}$ alone, 51 for $\mathrm{NO}_{2}$ and $\mathrm{PM}_{10}, 5$ for $\mathrm{PM}_{10}$ alone, 3 for $\mathrm{SO}_{2}$ alone, 2 for $\mathrm{NO}_{2}$ and $\mathrm{SO}_{2}$ and 1 for $\mathrm{PM}_{10}$ and $\mathrm{SO}_{2}$. In 115 (93.5\%) road traffic was the sole or predominant reason for the declaration and in the 2 for $\mathrm{NO}_{2}$ and $\mathrm{SO}_{2}$ road traffic was a major factor in the declaration. The other declarations were for industrial emissions.

Particles are recognised as being one of the most significant air pollutants so far as adverse health effects are concerned. They have been linked to respiratory problems (Anderson et al. [1], Dockery and Pope [2]), general mortality (Dockery et al. [3]), lung cancer and cardiopulmonary mortality (Pope et al. [4] and the onset of myocardial infarction (Peters et al. [5].

Hourly average concentrations of $\mathrm{PM}_{10}$ are measured at more than 60 locations in the UK with some or all of carbon monoxide, oxides of nitrogen (as $\mathrm{NO}, \mathrm{NO}_{2}$ and $\mathrm{NO}_{\mathrm{X}}$ ), ozone and sulphur dioxide. This Automatic Urban and Rural Network (AURN) comprises a total of 118 sites (October 2004) ranging from rural to roadside locations. The data are publicly available on the National Air Quality Information Archive (NAQIA) [6].

In general the lowest concentrations are found at the rural sites and increase through suburban and urban background/urban centre to roadside sites. Industrial sites have individual characteristics and will not be considered here. A significant limitation of the AURN is that only 6 of the operational $\mathrm{PM}_{10}$ sites in 2004 were roadside. There are a further 4 sites near motorways or trunk roads operated by TRL for the Highways Agency. Data from both networks are subject to strict QA/QC procedures to maximise data reliability.

Many Local Authorities also carry out their own monitoring in addition to the national network. Although this includes monitoring for $\mathrm{PM}_{10}$ the costs of operating the Tapered Element Oscillating Microbalance $\left(\mathrm{TEOM}^{\circledR}\right)$ to obtain hourly average data are sufficiently high as to limit the amount of such monitoring that is carried out.

The process of LAQM is now a rolling programme set out to 2010 with requirements to declare new AQMAs as identified. In addition to this is expected that there will be changes to the European Limit Values for $\mathrm{PM}_{10}$ which are likely to result in the UK objectives being tightened. The review and assessment process comprises 2 stages, an Update and Screening Assessment (USA) and a Detailed Assessment (DA). Only if the former reveals possible non-achievement of the objective is the DA necessary. Given the likelihood of tighter objectives for $\mathrm{PM}_{10}$ it is highly desirable for Local Authorities to have a relatively simple tool to assess concentrations at those locations for which they may have data for some pollutants but not for $\mathrm{PM}_{10}$. This work seeks to address this issue, at least for roadside locations.

\section{Methodology}

\subsection{General}

Earlier work (Muir [7], Muir et al. [8]) has described how long term average concentrations of each pollutant for each hour in the week have been calculated. 
These data have been further refined to enable weekdays and weekends and individual days of the week to be compared and to examine summer and winter average concentrations, these being defined as 1 April to 30 September and 1 October to 31 March respectively. This work has also described how a simple model has been constructed to calculate the additional amounts of $\mathrm{PM}_{10}$, here described as disaggregated concentrations, observed during air pollution episodes arising from emissions from road traffic.

The initial approach investigated is given in formula (1). It was, however, felt that this would be better expressed as formula (2) where $F$ is a factor dependent on the source type and strength.

[disaggregated $\left.\mathrm{PM}_{10}\right]_{\text {modelled }}=\left[\mathrm{PM}_{10}\right]_{\text {source }} \mathrm{X} \%$ increase $[$ other pollutant $]$

[disaggregated $\left.\mathrm{PM}_{10}\right]_{\text {modelled }}=\mathrm{F} \times\left(\left[\mathrm{PM}_{10}\right]_{\text {average }} \mathrm{X} \%\right.$ increase [other pollutant $\left.]\right)$ (2)

This is an oversimplification as it assumes that the total of the other pollutant measured at a particular site arises only from the one source.

It was necessary to assign values to the factor, F, for different sources and site locations in order to establish the validity of the method. In the case of road traffic the $30 \%$ contribution derived from the report of the UK Airborne Particles Expert Group (APEG [9]) for Urban Centre/Background locations led to a value of $F=0.3$ being selected. In a similar fashion values of $F=0.2$ and $F=0.5$ were assumed for Suburban and Roadside locations respectively representing $20 \%$ and $50 \%$ contributions of road traffic to long term average concentrations of $\mathrm{PM}_{10}$ in these site types. The earlier work demonstrated that these assumptions were generally valid although there were instances where agreement between modelled and measured data were poor. In the earlier work it was found that nitric oxide data rather than carbon monoxide data provided he best surrogate for road traffic sources of $\mathrm{PM}_{10}$ so here only nitric oxide data are used to represent road traffic derived $\mathrm{PM}_{10}$.

In order to address these disparities the original approach must be refined to incorporate data for other pollutants to allow for non-road traffic combustion sources (including industrial sources) and secondary particles. This leads to formula (3) as a first approximation.

$\left[\text { disaggregated } \mathrm{PM}_{10}\right]_{\text {modelled }}=\left(\mathrm{F}_{1} \mathrm{x}\left(\left[\mathrm{PM}_{10}\right]_{\text {average }} \mathrm{x} \%\right.\right.$ increase $\left.\left.[\mathrm{NO}]\right)\right)+\left(\mathrm{F}_{2} \mathrm{x}\right.$

$\left(\left[\mathrm{PM}_{10}\right]_{\text {average }} \mathrm{x} \%\right.$ increase $\left.\left.\left[\mathrm{SO}_{2}\right]\right)\right)+\left(\mathrm{F}_{3} \mathrm{x}\left(\left[\mathrm{PM}_{10}\right]_{\text {average }} \mathrm{x} \%\right.\right.$ increase $\left.\left.\left[\mathrm{O}_{3}\right]\right)\right)$ In this it has been assumed that increases in the concentrations of sulphur dioxide represent the contributions of industrial and other combustion sources and ozone concentrations represent photochemical activity. Finally to calculate hourly average concentrations it is necessary to add the appropriate long-term hourly average concentration of $\mathrm{PM}_{10}$ to the modelled disaggregated concentrations.

This approach was tested using data from two AURN sites in Glasgow, Glasgow Centre (Urban Centre) and Glasgow Kerbside (Roadside). At the former $\mathrm{CO}, \mathrm{NO}_{\mathrm{x}}, \mathrm{O}_{3}, \mathrm{PM}_{10}$ and $\mathrm{SO}_{2}$ and at the latter only $\mathrm{CO}, \mathrm{NO}_{\mathrm{x}}$ and $\mathrm{PM}_{10}$ are measured. These two sites are about $500 \mathrm{~m}$ apart (Brown, [10]) so it was felt that the concentrations of $\mathrm{O}_{3}$ and $\mathrm{SO}_{2}$ measured at the Glasgow Centre site would adequately represent those which might be expected at the roadside site.

Because the average concentrations of $\mathrm{PM}_{10}$ at roadside sites are higher than those at background sites it is necessary to account for this difference in the final 
calculation of the roadside concentrations of $\mathrm{PM}_{10}$. Examination of data from roadside sites and the closest background sites shows that the roadside enhancement of $\mathrm{PM}_{10}$ is approximately $35 \%$. This does vary from site to site but it provides as realistic a start point as it is possible to achieve at this stage. The outcome of this is that the concentrations of $\mathrm{PM}_{10}$ at the Glasgow kerbside site were initially modelled using formula (4) and then using formula (5).

$\left[\mathrm{PM}_{10}\right]_{\text {Glasgow Kerbside }}=\left(\left(\left[\mathrm{PM}_{10}\right]_{\text {Glasgow Centre }}\right)+\left(\mathrm{F}_{1} \times\left(\left[\mathrm{PM}_{10}\right]_{\text {Glasgow Centre }} \mathrm{x} \%\right.\right.\right.$ increase

$[\mathrm{NO}]))) \times 1.35$

$\left[\mathrm{PM}_{10}\right]_{\text {Glasgow Kerbside }}=\left(\left(\left[\mathrm{PM}_{10}\right]_{\text {Glasgow Centre }}\right)+\left(\mathrm{F}_{1} \mathrm{x}\left(\left[\mathrm{PM}_{10}\right]_{\text {Glasgow Centre }} \mathrm{x} \%\right.\right.\right.$ increase $[\mathrm{NO}]))+\left(\mathrm{F}_{2} \times\left(\left[\mathrm{PM}_{10}\right]_{\text {Glasgow Centre }} \mathrm{x} \%\right.\right.$ increase $\left.\left.\left[\mathrm{SO}_{2}\right]\right)\right)+\left(\mathrm{F}_{3} \times\left(\left[\mathrm{PM}_{10}\right]_{\text {Glasgow Centre }}\right.\right.$ $\mathrm{x} \%$ increase $\left.\left.\left.\left[\mathrm{O}_{3}\right]\right)\right)\right) \times 1.35$

\section{Results and discussion}

Figures $1 \mathrm{a}$ and $\mathrm{b}$ compare the hourly average concentrations of $\mathrm{PM}_{10}$ measured at Glasgow Kerbside and the corresponding concentrations modelled using formula (4), that is using NO only for 2 months, July 1997 and February 1998 representing typical summer and winter months.

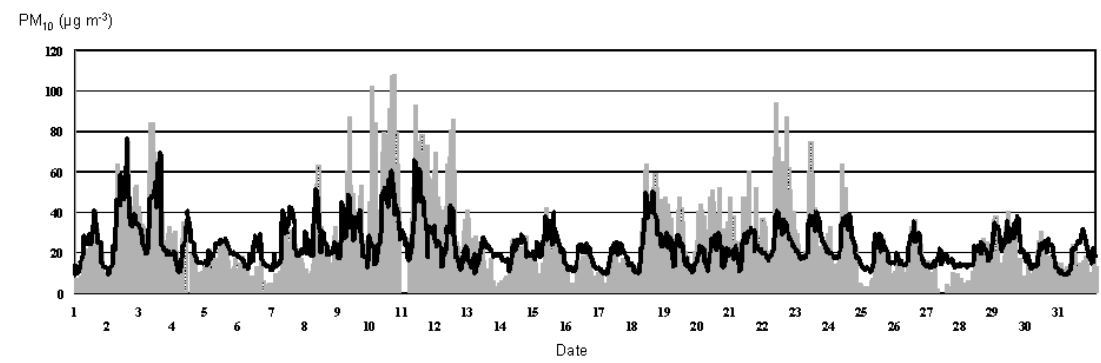

(a) July1997

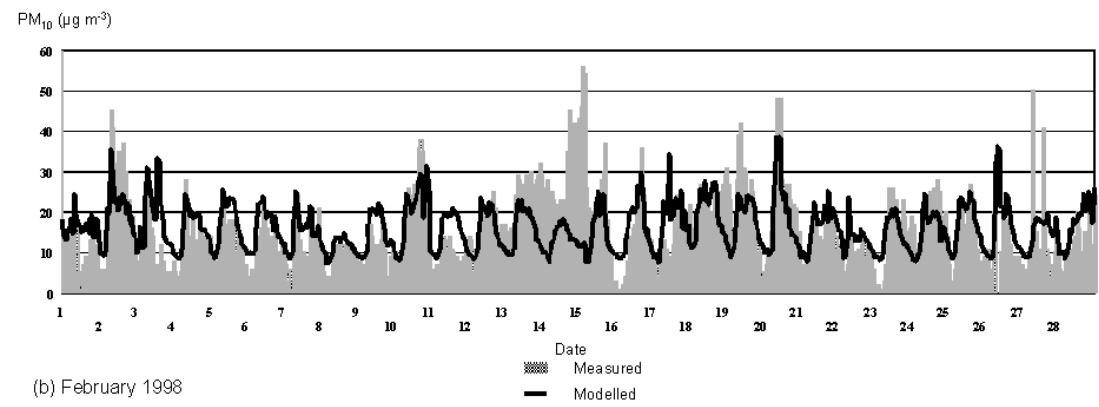

Figure 1: $\quad$ Measured and modelled concentrations of $\mathrm{PM}_{10}$ using $\mathrm{NO}$ data only.

For much of the time during these months the modelled concentrations of $\mathrm{PM}_{10}$ are very close to the measured concentrations. In both cases there are also 
periods of significant underestimation and some of overestimation. Figures 2 a and $b$ show the comparable data when formula (5) is used for the modelling. In this case all data for sulphur dioxide and ozone were used and, making an initial assumption that all the differences in concentrations of these would be reflected in differences of concentrations of $\mathrm{PM}_{10}$, both $\mathrm{F}_{2}$ and $\mathrm{F}_{3}$ were assigned a value of unity.

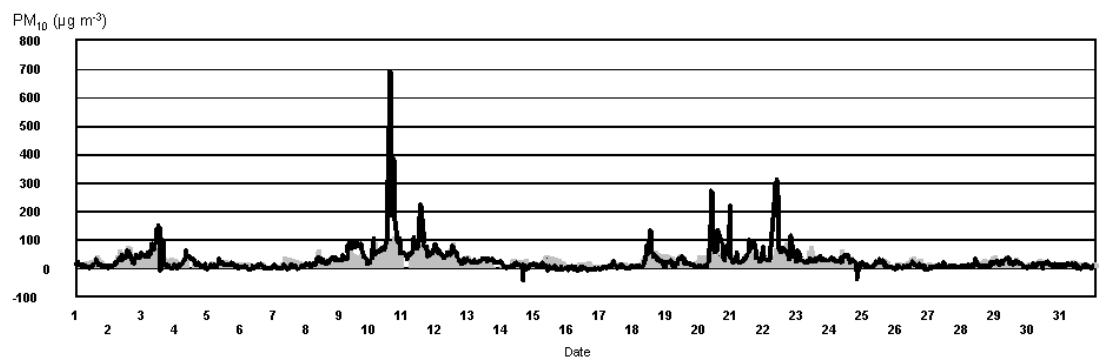

(a) July1997

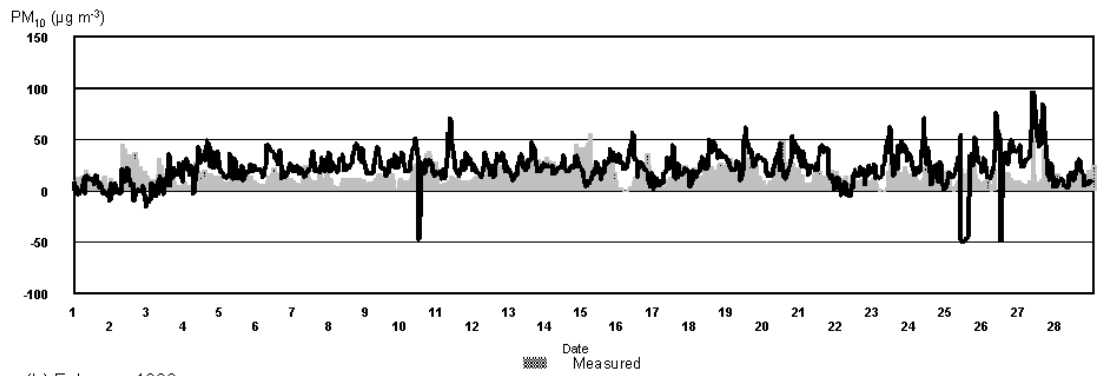

(b) February 1998

- Modelled

Figure 2: $\quad$ Measured and modelled concentrations of $\mathrm{PM}_{10}$ using $\mathrm{NO}, \mathrm{SO}_{2}$ and ozone data.

These show a generally poorer agreement between measured and modelled data although some of the periods of underestimation are corrected. A particular problem with these calculations is that they result in reduced modelled concentrations at times where the simpler model produced good agreement.

Detailed examination of the data showed that much of this reduction, at least during February 1998 was due to the allowance for ozone. Although it is reasonable to expect secondary particle formation at any time of the year (APEG [9], AQEG [11]) it is not expected that this would be associated with elevated concentrations of photo-chemically formed ozone in the winter months. This examination also showed that although there were some periods when concentrations of sulphur dioxide were higher than average in general the measured hourly average concentrations were lower than the long term average concentrations giving a negative contribution to the modelled concentrations of $\mathrm{PM}_{10}$. 
This suggests a refined approach where only data for sulphur dioxide and ozone which may be significantly associated with increased concentrations of $\mathrm{PM}_{10}$ are used in the calculations. The reasoning here is that in much of the UK concentrations of sulphur dioxide are usually very low and below the annual average concentrations which will result in the negative contributions to the modelled concentrations of $\mathrm{PM}_{10}$. Table 1 lists examples for Bristol Centre.

Table 1: Hourly average concentrations of $\mathrm{SO}_{2}$ less than average concentrations.

\begin{tabular}{|l|c|c|c|c|}
\hline Year & $1993-2004$ & 1993 & 1997 & 2003 \\
\hline Average $\left[\mathrm{SO}_{2}\right]\left(\mu \mathrm{g} \mathrm{m}^{-3}\right)$ & 4.2 & 8.3 & 3.6 & 2.7 \\
\hline Percentage less than average & $72 \%$ & $68 \%$ & $75 \%$ & $77 \%$ \\
\hline
\end{tabular}

In a similar fashion concentrations of ozone will usually be very low during winter pollution episodes caused by road traffic emissions. This is not perceived as a problem in the case of nitric oxide as here negative disaggregated concentrations are usually small in terms of percentage of the average concentration whereas in the other cases they are frequently large. Figures 3 a and $b$ illustrate the measured and modelled concentrations of $\mathrm{PM}_{10}$ with negative contributions from ozone and sulphur dioxide removed. These show a much improved agreement between measured and modelled concentrations of $\mathrm{PM}_{10}$.

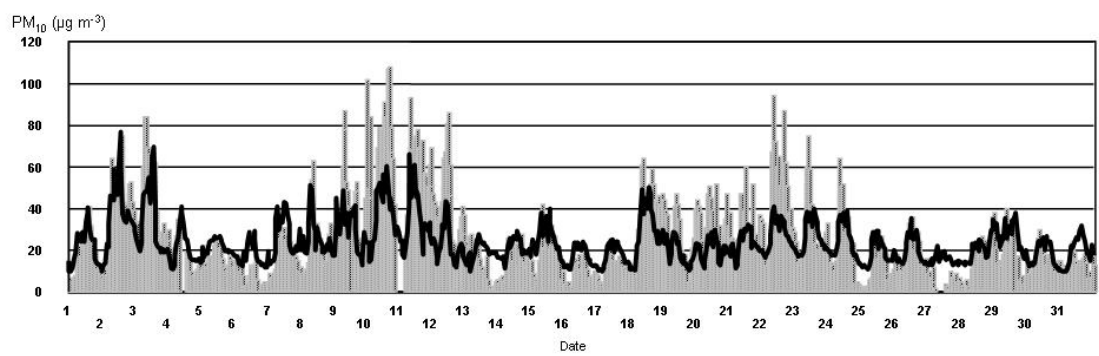

(a) July 1997

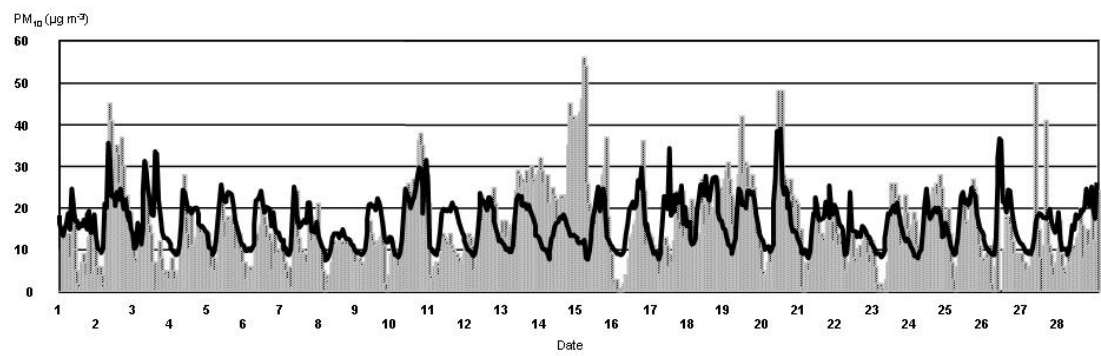

(b) February 1998

- Measured

Figure 3: $\quad$ Measured and modelled concentrations of $\mathrm{PM}_{10}$ using $\mathrm{NO}$, and filtered $\mathrm{SO}_{2}$ and ozone data. 
A final refinement was made as a result of a suggestion made by Dr. D Middleton [12]. This was to add the hourly average concentrations of ozone to the corresponding concentrations of nitrogen dioxide to produce an approximation of concentrations of atmospheric oxidants (OX) and to replace the disaggregated concentrations of ozone with disaggregated concentrations of OX. This approach has also been applied to analysis of $\mathrm{NO}_{\mathrm{X}}$ data (Jenkin, $[13,14]$. When this was done the problem of the negative disaggregated concentrations of ozone disappeared. Figures $4 \mathrm{a}$ and $\mathrm{b}$ show the results of this approach. This appears to be the best agreement of the scenarios tested here. There are still some discrepancies. One particular example is between 13 and 15 February 1998. It is, however, conceivable that the additional $\mathrm{PM}_{10}$ observed here was the consequence of some activity, such as construction (Muir, [7], Muir et al. 8]) giving rise to increased emissions of particles with little or no increased emissions of other measured pollutants.

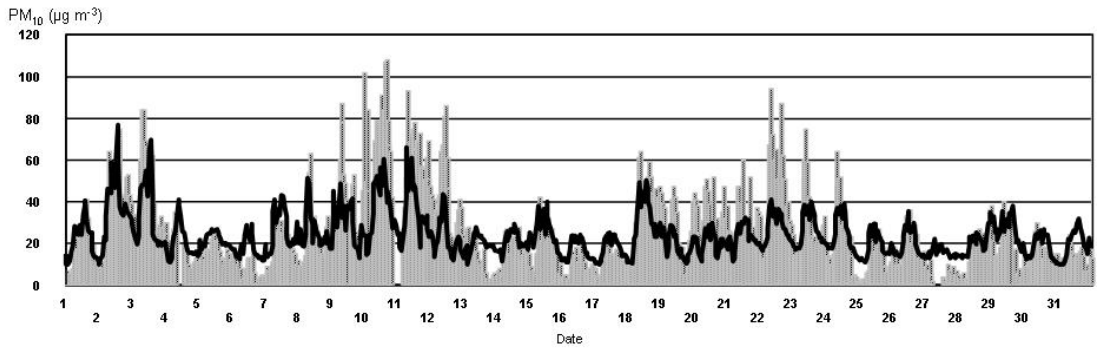

(a) July1997

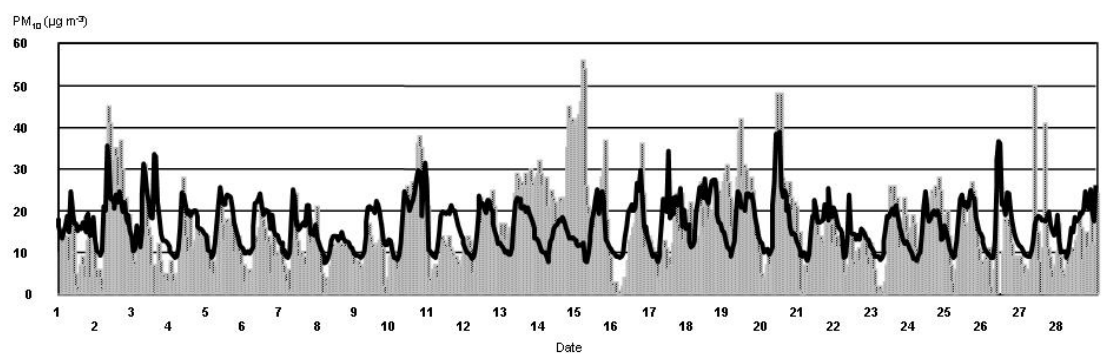

(b) February 1998

$$
\text { - Measured }
$$

Figure 4: Measured and modelled concentrations of $\mathrm{PM}_{10}$ at Glasgow kerbside using $\mathrm{NO}, \mathrm{SO}_{2}$ and ozone data.

\section{Conclusions}

This work demonstrates that it is possible to produce modelled hourly average concentrations of $\mathrm{PM}_{10}$ at a roadside site using a combination of data for pollutants emitted by road traffic measured at that site and data for other pollutants from another nearby site that are adequate for the initial stages of 
Review and Assessment of air quality under the UK's LAQM regime. Further work is needed to determine how applicable the techniques used here are to other locations where the sites from which data have been drawn are separated by a greater distance than was the case here.

It is also necessary to make the point that the methodology described here cannot replace properly ratified measured data in the more detailed stages of the LAQM process.

\section{Acknowledgements}

All the raw data on concentrations of the pollutants used in this work was drawn from the National Air Quality Information Archive maintained by netcen on behalf of the Department for Environment, Food and Rural Affairs.

\section{References}

[1] Anderson H.R., de Leon A.P., Bland J.M., Bower J.S., Emberlin J., Strachan D.P., Air pollution, pollens and daily admissions for asthma in London 1987 - 92, Thorax, 53(10), pp. 1287-1298, 1998.

[2] Dockery D.W., Pope C.A., Acute respiratory effects of particulate air pollution. Annual Review of Public Health. 15, pp 107-132,1994.

[3] Dockery D.W., Pope C.A., Xu X., Spengler J.D., Ware J.H., Fay M.E., Ferris B.G., Speizer F.E., An association between air pollution and mortality in six US cities. New England Journal of Medicine, 329 (24), pp 1753-1759, 1993.

[4] Pope C.A., Burnett R.T., Thun M.J., Calle E.E., Krewski D., Ito K., Thurston G.D., Lung Cancer, Cardiopulmonary Mortality and Long-term Exposure to Fine particulate Matter. Journal of the American Medical Association, 287 (9), pp 1132-1141, 2002.

[5] Peters Annette, von Klot Stephanie, Heier Margit, Trentinaglia Ines, Hörmann Allmut, Wichmann H. Erich, Löwel Hannelore. Exposure to Traffic and the Onset of Myocardial Infarction. New England Journal of Medicine, 351 (17), 1721-1730, 2004.

[6] NAQIA, www.airquality.co.uk.

[7] Muir D. Source apportionment of PM 10 during pollution episodes. Unpublished $\mathrm{PhD}$ thesis. University of the West of England, Bristol, pp. 481, 2003.

[8] Muir D., Longhurst J.W.S., Tubb A., Characterisation and Quantification of the Sources of $\mathrm{PM}_{10}$ during Air Pollution Episodes in the UK, Science of the Total Environment, in press.

[9] APEG. Airborne Particles Expert Group Report: Source Apportionment of Airborne Particulate Matter in the United Kingdom. UK Department of the Environment, Transport \& the Regions, London, 1999.

[10] Brown, A., Personal communication, January 2003, Environmental Protection Services, Glasgow City Council, UK. 
[11] AQEG. 2004. Air Quality Expert Group Report: Particulate Matter in the United Kingdom (Draft). UK Department for Environment, Food \& Rural Affairs, London.

[12] Middleton, D, Personal communication, July 2003, Met Office.

[13] Jenkin, M.E., Analysis of sources and partitioning of oxidant in the UK Part 1: the $\mathrm{NO}_{\mathrm{X}}$ dependence of annual mean concentration of nitrogen dioxide and ozone, Atmospheric Environment, 38 (30), 5117-5129, 2004.

[14] Jenkin, M.E., Analysis of sources and partitioning of oxidant in the UK Part 2: contributions of nitrogen dioxide emissions and background ozone at a kerbside location in London, Atmospheric Environment, 38 (30), 5117-5129, 2004. 